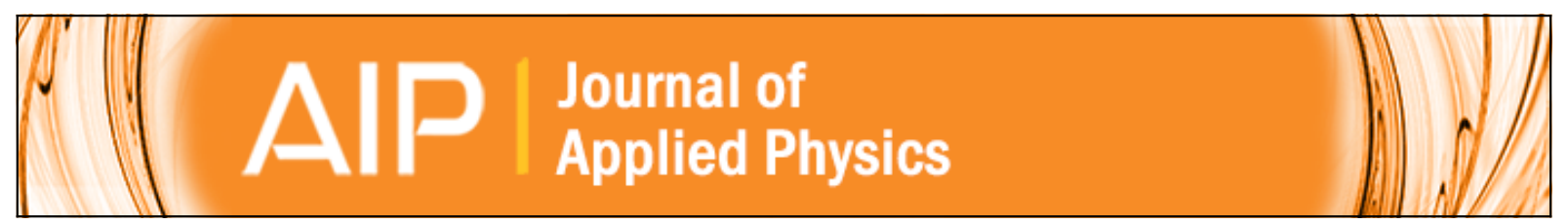

Thermally induced modifications on bonding configuration and density of defects of plasma deposited SiO $\mathrm{x}: \mathrm{H}$ films

E. San Andrés, A. del Prado, I. Mártil, G. González-Daz, D. Bravo, and F. J. López

Citation: Journal of Applied Physics 92, 1906 (2002); doi: 10.1063/1.1495068

View online: http://dx.doi.org/10.1063/1.1495068

View Table of Contents: http://scitation.aip.org/content/aip/journal/jap/92/4?ver=pdfcov

Published by the AIP Publishing 


\title{
Thermally induced modifications on bonding configuration and density of defects of plasma deposited $\mathrm{SiO}_{x}: \mathrm{H}$ films
}

\author{
E. San Andrés, A. del Prado, I. Mártil, ${ }^{a)}$ and G. González-Díaz \\ Departamento Física Aplicada III, Facultad de Ciencias Físicas, Universidad Complutense, 28040 Madrid, \\ Spain \\ D. Bravo and F. J. López \\ Departamento Física de Materiales, Facultad de Ciencias, C-IV, Universidad Autónoma, 28049 Madrid, \\ Spain
}

(Received 23 April 2002; accepted for publication 30 May 2002)

The bonding configuration, hydrogen evolution, and defect content of rapid thermally annealed (RTA) $\mathrm{SiO}_{x}: \mathrm{H}$ films of different compositions were studied. Infrared absorption measurements showed that all the hydrogen present in the films is lost at annealing temperatures below $600{ }^{\circ} \mathrm{C}$ without any change in the oxygen to silicon ratio of the films. The activation energy of the hydrogen release is in the $0.21-0.41 \mathrm{eV}$ range independently of film composition, suggesting that the process occurs via network bond reactions. For annealing temperatures higher than $700{ }^{\circ} \mathrm{C}$, a change in the $\mathrm{Si}-\mathrm{O}-\mathrm{Si}$ stretching wave number from the initial unannealed value to the $1070-1080 \mathrm{~cm}^{-1}$ range was promoted, independently of the initial film composition. Electron spin resonance measurements showed that all the films contain two type of bulk paramagnetic defects: the $E^{\prime}$ center $\left(\bullet \mathrm{Si} \equiv \mathrm{O}_{3}\right)$ and the silicon dangling bond center $\left(\bullet \mathrm{Si} \equiv \mathrm{Si}_{3}\right)$. The RTA process promotes a general decrease of defect concentration for annealing temperatures below $400{ }^{\circ} \mathrm{C}$. At higher temperatures, $E^{\prime}$ center disappears, and the $\cdot \mathrm{Si} \equiv \mathrm{Si}_{3}$ center increases its concentration up to the $10^{17}-10^{18} \mathrm{~cm}^{-3}$ range. This suggests that the RTA at higher temperatures promotes the formation of a high-quality, almost defect-free, $\mathrm{SiO}_{2}$ matrix in which highly defective $\mathrm{Si}$ nanocrystals are also formed, where the - $\mathrm{Si} \equiv \mathrm{Si}_{3}$ centers are located. (C) 2002 American Institute of Physics. [DOI: 10.1063/1.1495068]

\section{INTRODUCTION}

Thermally grown silicon dioxide $\left(\mathrm{SiO}_{2}\right)$ is the most extensively used dielectric in the microelectronic industry because its excellent electrical characteristics and the high quality of the $\mathrm{SiO}_{2} / \mathrm{Si}$ interface. It is well known that the $\mathrm{Si} / \mathrm{SiO}_{2}$ interface is composed of stoichiometric $\mathrm{SiO}_{2}$ within 4-6 $\AA$ of the interface, where Si-rich suboxide $\left(\mathrm{SiO}_{x}, x\right.$ $<2$ ) layers are present. ${ }^{1}$ The presence of these suboxide layers strongly limits the electrical characteristics of devices where the $\mathrm{Si} / \mathrm{SiO}_{2}$ interface plays a main role, like fieldeffect transistors.

The aggressive scale of integration also leads to high gate capacitances, and these high gate capacitances require an ultrathin $\mathrm{SiO}_{2}$ film, which is too leaky for device performance. Much effort has been invested into finding a high- $k$ dielectric with interface characteristics comparable to thermal $\mathrm{SiO}_{2}$ and a higher physical thickness to reduce gate leakage. Most of these dielectrics contain oxygen, which usually reacts with the silicon of the substrate leading to an interfacial suboxide layer. These suboxides put severe limitations on the device performance because they lead to a reduction of the total effective relative permittivity of the dielectric, being the advantage of the high dielectric constant of these materials eventually lost. These suboxide films have been detected by several different methods like Fourier transform

a) Author to whom correspondence should be addressed; electronic mail: imartil@ fis.ucm.es infrared spectroscopy (FTIR), high-resolution transmission electron microscopy, secondary ion mass spectroscopy, $\mathrm{x}$-ray photoelectron spectroscopy, ${ }^{2}$ etc., in some promising materials, like the $\mathrm{Ta}_{2} \mathrm{O}_{5} / \mathrm{Si}$ system, ${ }^{3}$ the $\mathrm{TiO}_{2} / \mathrm{Si}$ system, ${ }^{4}$ or the ( $\mathrm{BaSr}) \mathrm{TiO}_{3} / \mathrm{Si}$ system. ${ }^{5}$ Also, Lucovsky et al. with their constraint theory deduced the necessity of this interfacial suboxide film to reach good electrical characteristics. ${ }^{6,7}$

It is also known that during thermal anneals, $\mathrm{SiO}_{x}: \mathrm{H}$ films experiences the following network reaction: ${ }^{1,8}$

$$
\mathrm{SiO}_{x} \rightarrow(x / 2) \mathrm{SiO}_{2}+(1-x / 2) \mathrm{Si},
$$

i.e., the annealing promotes the formation of both stoichiometric $\mathrm{SiO}_{2}$ and $\mathrm{Si}$ clusters of nanometer size [in the following, nanocrystalline silicon nc-Si]. ${ }^{9}$ This network reaction takes place both at the transition region of the $\mathrm{SiO}_{2} / \mathrm{Si}$ interface and in bulk thin films. ${ }^{2}$ These nanoclusters are highly defective, but by now it is not clearly known where these defects are present or whether they are in the bulk of the cluster or at the interface with the $\mathrm{SiO}_{2}$ matrix within they are embedded. Much work has been done to study the luminescence properties of such nc-Si. ${ }^{10,11}$ On the contrary, only a few papers dealing with the type of defects present in these nc-Si can be found in literature. ${ }^{12,13}$

Reaction (1) does not contain information about other processes also taking place during thermal treatments: Defect evolution and hydrogen release, that occurs at moderate temperatures. ${ }^{14}$ In fact, thermal annealing can modify both the type of defect present in the film and also its concentration. The influence of rapid thermal annealing (RTA) on the 
evolution of defects has been recently analyzed by our group on stoichiometric, almost hydrogen free, $\mathrm{SiO}_{2}$ films. ${ }^{15}$

The aim of this work is to analyze the thermal behavior of bulk $\mathrm{SiO}_{x}: \mathrm{H}$ films deposited by the electron cyclotron resonance (ECR) plasma method in a wide range of film composition. The main emphasis will be paid to the analysis of the hydrogen release and to the changes that the type and concentration of defects undergo during thermal anneals of such films.

\section{EXPERIMENT}

Several series of films of 200-300 nm thick were deposited onto a Radio Corporation of America (RCA) cleaned high-resistivity silicon wafers [ $80 \Omega \mathrm{cm} \mathrm{Si}$ (111)] polished on both sides. Deposition processes were conducted in a homemade chamber attached with an ECR Astex 4500 reactor. The deposition chamber was pumped by a turbomolecular pump, reaching a base pressure of $6 \times 10^{-7}$ mbar. Further details of the deposition system are given elsewhere. ${ }^{16}$ The precursor gases used were high-purity $\mathrm{SiH}_{4}$ and $\mathrm{O}_{2}$, and films of different compositions were obtained depending on gases flow ratio, that we define in this article in the same way that Bulkin et al., ${ }^{17}$ i.e., $\mathbf{R}_{\mathbf{b}}=\left[\mathrm{SiH}_{4}\right] /\left(\left[\mathrm{SiH}_{4}\right]+\left[\mathrm{O}_{2}\right]\right) . \mathbf{R}_{\mathbf{b}}$ values comprised between 0.2 and 0.9 were used in this study. For all depositions, the total gas flow, chamber pressure, and microwave power were kept constant at $10.5 \mathrm{sccm}$, 0.7 mTorr, and $100 \mathrm{~W}$, respectively. Substrates were not intentionally heated and the deposition temperature was estimated to be in the $50{ }^{\circ} \mathrm{C}, 60^{\circ} \mathrm{C}$ range.

Low values of $\mathbf{R}_{\mathbf{b}}(<0.4)$ give stoichiometric, hydrogen free $\mathrm{SiO}_{2}$ films, while higher values (in the 0.6-0.9 range) produce off-stoichiometric films with high hydrogen content, that we will refer as $\mathrm{SiO}_{x}: \mathrm{H}$ (being $x$ the oxygen to silicon ratio of films, $x<2$ ). In all the cases, film thickness was in the $20-30 \mathrm{~nm}$ range.

After the deposition process, the wafers with the suboxide deposited at any particular value of $\mathbf{R}_{\mathbf{b}}$ were cleaved into several squared pieces $(1 \times 1 \mathrm{~cm})$ to subject the film to RTA processes at different temperatures. In this way, it is assured that the only difference between the films is the RTA temperature. As-deposited, unannealed samples were also saved to be used as a reference.

RTA processes were performed in a Modular Process Technology furnace model RTP-600, equipped with a graphite susceptor. Samples were annealed for $30 \mathrm{~s}$ in an argon atmosphere at temperatures ranging between $300^{\circ} \mathrm{C}$ and $1000^{\circ} \mathrm{C}$ in steps of $100^{\circ} \mathrm{C}$.

Films were characterized by means of (FTIR) Spectroscopy in the $400-4000 \mathrm{~cm}^{-1}$ range with a Nicolet Magna-IR 750 series II spectrometer working in the transmission mode at normal incidence. The spectrum of the film was obtained subtracting the substrate spectrum from the total signal (substrate + deposited film). After subtracting the substrate spectrum, the spectra baseline was corrected and the main characteristics thus measured. The peak position of the main $\mathrm{Si}-\mathrm{O}-\mathrm{Si}$ stretching band was used as a measure of the oxygen to silicon ratio $(\mathrm{O} / \mathrm{Si}=x)$ of the as-grown films fol-

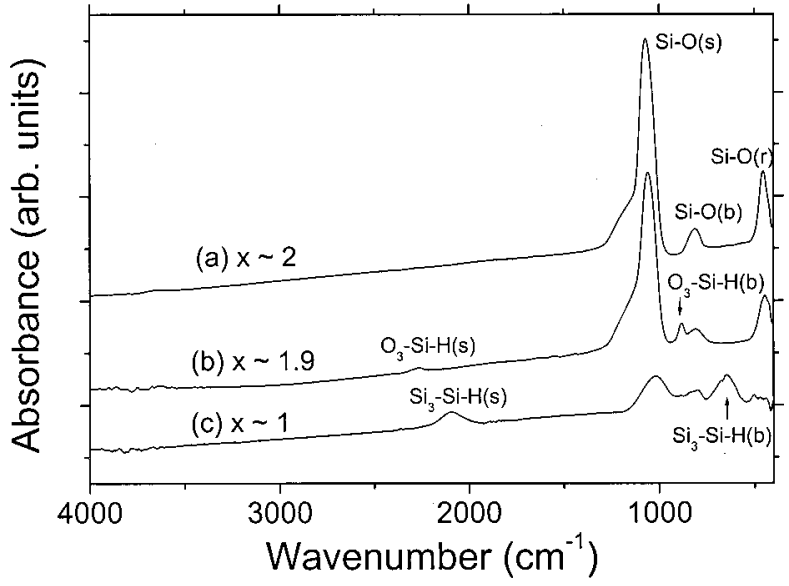

FIG. 1. FTIR spectra of three significant film compositions: stoichiometric (a), near stoichiometric (b), and off-stoichiometric (c). The main features have been identified.

lowing the papers of the North Carolina State University group. ${ }^{1,18}$

Electron spin resonance (ESR) characterization was performed at room temperature with a Bruker ESP $300 \mathrm{E}$ spectrometer operating in the $X$ band at a microwave power of $0.5 \mathrm{~mW}$ which is low enough to prevent the saturation of the signal. In order to enhance the ESR signal, each film used was cut in five pieces of $0.2 \times 1 \mathrm{~cm}$ after annealing. These five pieces were stacked, so the effective thickness of each film was between $1000-1500 \mathrm{~nm}$. The density of paramagnetically active centers was quantified by comparison with the signal of a calibrated weak pitch standard. ${ }^{19}$

\section{RESULTS}

We have deposited films with five different gas ratios $\left(\mathbf{R}_{\mathbf{b}}=0.23,0.5,0.67,0.8\right.$, and 0.91) which lead to films with different as-grown compositions, determined as was previously detailed in the experimental section by means of the peak position of the $\mathrm{Si}-\mathrm{O}-\mathrm{Si}$ stretching band. These samples permit us to explore a wide range of suboxide characteristics: For the lower gas ratio $\left(\mathbf{R}_{\mathbf{b}}=0.23\right)$ films are stoichiometric, hydrogen free $\mathrm{SiO}_{2}$. These will be called from now on stoichiometric films. $\mathbf{R}_{\mathbf{b}}=0.5$ produces nearly stoichiometric films $\left(\mathrm{SiO}_{x}: \mathrm{H}, x \approx 1.9\right)$ with a low hydrogen content, that we will define in this article as near-stoichiometric samples. When the oxygen content in the chamber is low (films with $\mathbf{R}_{\mathbf{b}}=0.67,0.8$, and 0.91), the films present a high hydrogen content with $x$ values of $1.4,1$, and 0.9 , respectively. We will define these films as off-stoichiometric samples. Because they present very similar characteristics and trends, in some parts of the article, we will discuss their behavior together for the sake of clarity.

In Fig. 1, we present the FTIR spectra without any thermal treatment of three representative samples (stoichiometric, near-stoichiometric, and as a representative of the off-stoichiometric set, a $x \approx 1$ film). In Fig. 1, the main features of the spectra have been marked:

(a) The stoichiometric film [Fig. 1(a)] presents the well known vibration modes of the $\mathrm{Si}-\mathrm{O}$ bond: stretching 
at $1071 \mathrm{~cm}^{-1}$ with a shoulder at $1123 \mathrm{~cm}^{-1}$, bending located at $813 \mathrm{~cm}^{-1}$, and rocking at $465 \mathrm{~cm}^{-1}$. No evidence of bonded hydrogen has been found, either in the $\mathrm{Si}-\mathrm{H}$ or in the $\mathrm{O}-\mathrm{H}$ configuration, so the hydrogen content should be lower than $1 \%$, the detection limit of the technique.

(b) In the near-stoichiometric films [Fig. 1(b)], in addition to the above-mentioned peaks, the presence of hydrogen is deduced by a small peak at $2260 \mathrm{~cm}^{-1}$ and another one at $881 \mathrm{~cm}^{-1}$. These two features are, respectively, the stretching and bending mode of the $\mathrm{O}_{3}-\mathrm{Si}-\mathrm{H}$ bonding configuration. ${ }^{20}$

(c) The off-stoichiometric films [Fig. 1(c), corresponding to a film with $x \approx 1$ ] present a much higher content of hydrogen bonded to silicon, as deduced by the areas of the two peaks located at 2095 and $645 \mathrm{~cm}^{-1}$. These peaks are related to the stretching and bending mode of the $\mathrm{Si}_{3}-\mathrm{Si}-\mathrm{H}$ bonding configuration respectively. ${ }^{20}$ Due to the low oxygen content of the films, the area of the $\mathrm{Si}-\mathrm{O}$ stretching mode, located at $1020 \mathrm{~cm}^{-1}$, is much lower than it was in the stoichiometric and nearstoichiometric films. Also, the $\mathrm{Si}-\mathrm{O}$ bending and rocking modes are not detected in the as-deposited samples, mainly due to their smaller intensity.

The hydrogen release and film quality improvement with annealing temperature of the off-stoichiometric films can be followed from results in Fig. 2, where it is presented the evolution of the FTIR spectrum of a sample with $x \approx 1$. On the as-deposited film, the presence of hydrogen is recognized by a peak at $2095 \mathrm{~cm}^{-1}$ (commonly associated to the $\mathrm{Si}_{3}-\mathrm{Si}-\mathrm{H}$ stretching vibration mode), ${ }^{21}$ and a more intense peak at $645 \mathrm{~cm}^{-1}$ (associated to the $\mathrm{Si}_{3}-\mathrm{Si}-\mathrm{H}$ bending vibration mode). ${ }^{21}$ The area of these peaks is in direct relation to the hydrogen content of the film. The annealing treatment gives no significant change in the $\mathrm{Si}-\mathrm{O}$ stretching wave number of the maximum for annealing temperatures below $600{ }^{\circ} \mathrm{C}$, nor in the full width at half maximum (FWHM). At higher temperatures $\left(>900^{\circ} \mathrm{C}\right)$, the $\mathrm{Si}-\mathrm{O}$ stretching peak position reach values comparable to stoichiometric $\mathrm{SiO}_{2}$. Also a shoulder in the $\mathrm{Si}-\mathrm{O}$ stretching peak

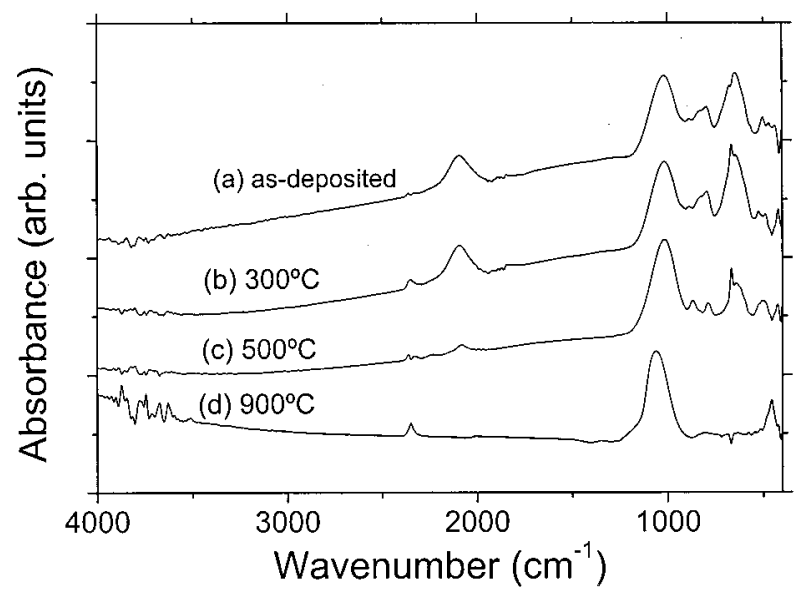

FIG. 2. FTIR Spectra for an off-stoichiometric film $(x \approx 1)$ as deposited (a), annealed at $300^{\circ} \mathrm{C}(\mathrm{b}), 500{ }^{\circ} \mathrm{C}(\mathrm{c})$, and $900^{\circ} \mathrm{C}(\mathrm{d})$.

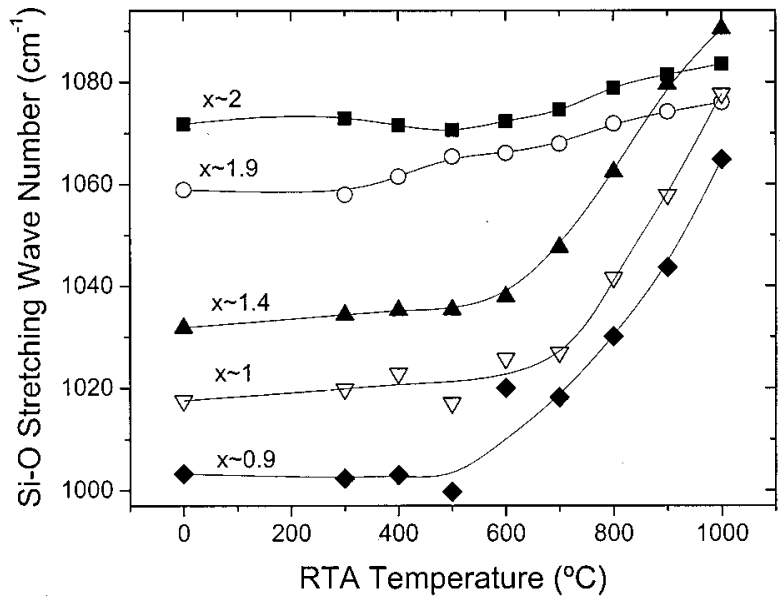

FIG. 3. Peak position of the $\mathrm{Si}-\mathrm{O}-\mathrm{Si}$ stretching band as a function of RTA temperature for several samples of five different initial oxygen to silicon ratios. Lines are drawn as a guide for the eye.

and the $\mathrm{Si}-\mathrm{O}$ rocking and bending modes make apparition at these temperatures, as can be seen in Fig. 2(d) (A more complete discussion on the $\mathrm{Si}-\mathrm{O}$ bonding behavior will be given later). From Fig. 2(d), it is clear that the hydrogen effusion takes place at temperatures between $300^{\circ} \mathrm{C}$ and $600^{\circ} \mathrm{C}$, being the hydrogen totally released for RTA temperatures above $600^{\circ} \mathrm{C}$.

In Fig. 3, we present the dependence of the peak position of the main $\mathrm{Si}-\mathrm{O}-\mathrm{Si}$ stretching band as a function of the RTA temperature for several samples of the five different initial compositions. In Fig. 4, we show the FWHM of the main stretching $\mathrm{Si}-\mathrm{O}-\mathrm{Si}$ peak as a function of the RTA temperature for the same films as in Fig. 3. From the results of Figs. 3 and 4, we can deduce the following characteristics of the annealed films:

In the stoichiometric $\mathrm{SiO}_{2}$ film, the peak position of the stretching band experiences a minor change with the RTA (from 1072 to $1080 \mathrm{~cm}^{-1}$ ), while the FWHM decreases from 89 to $80 \mathrm{~cm}^{-1}$. The behavior of the near-stoichiometric

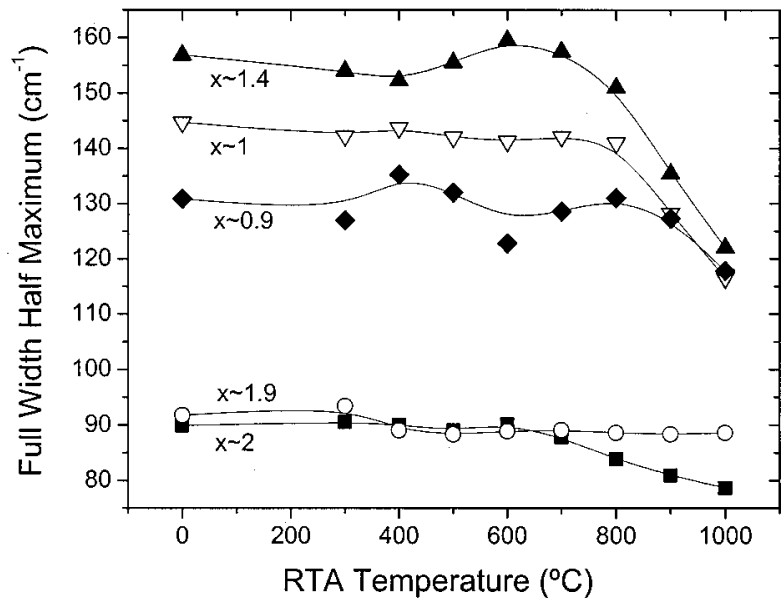

FIG. 4. FWHM of the $\mathrm{Si}-\mathrm{O}-\mathrm{Si}$ stretching band as a function of RTA temperature for the same samples quoted in Fig. 1. Lines are drawn as a guide for the eye. 


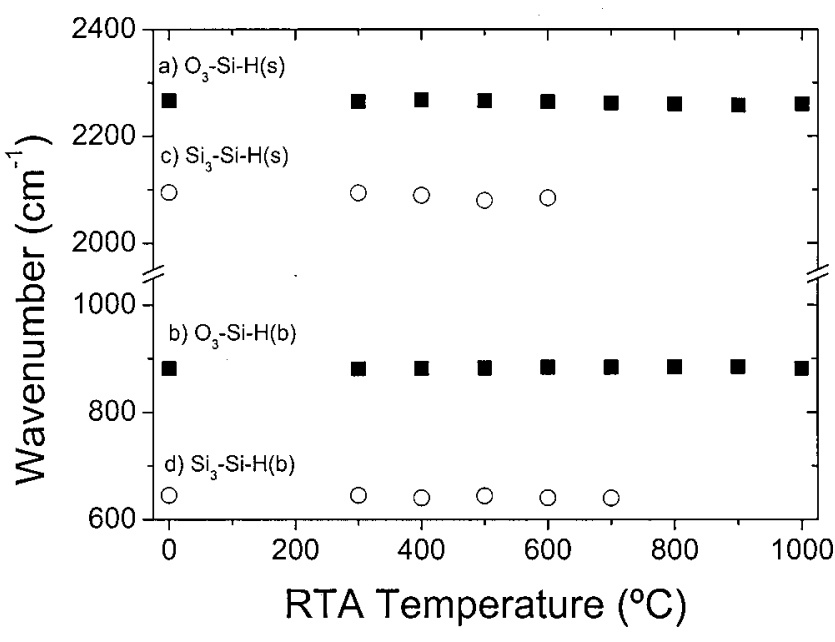

FIG. 5. Maximum wavenumbers of $\mathrm{Si}-\mathrm{H}$ related peaks for a nearstoichiometric film [closed squares, (a) and (b) corresponding to the stretching and bending vibration, respectively] and an off-stoichiometric film [open squares, (c) and (d) corresponding to the stretching and bending vibration respectively].

$\mathrm{SiO}_{x}: \mathrm{H}$ film is very similar to the $\mathrm{SiO}_{2}$ sample, as Figs. 3 and 4 evidence, with the main difference that these films contain hydrogen. The hydrogen is mainly present in the IR spectra as $\mathrm{Si}-\mathrm{H}$ stretching and $\mathrm{Si}-\mathrm{H}$ bending vibration modes [with peak positions located at 2260 and $881 \mathrm{~cm}^{-1}$, respectively, as was shown in Fig. 1(b)]. In Figs. 5(a) and $5(\mathrm{~b})$, we present the evolution of the $\mathrm{Si}-\mathrm{H}$ stretching and bending peak positions during annealing. As can be seen, the wave number of the peaks did not experience any significant change. This is an indication that the oxygen to silicon ratio $(x)$ of films did not experience modifications during annealing. ${ }^{22}$ In Fig. 5, we have also included the peak positions of hydrogen related vibrations versus RTA temperature for an off-stoichiometric sample [Figs. 5(c) and 5(d)]. As in the near-stoichiometric film, no changes in the $\mathrm{Si}-\mathrm{H}$ peak position are observed, suggesting again that in the offstoichiometric samples, there are no changes in the oxygen to silicon ratio upon annealing.

The total concentration of $\mathrm{Si}-\mathrm{H}$ bonds can be extracted from the $\mathrm{Si}-\mathrm{H}$ stretching band using: ${ }^{7,23}$

$$
[H]=A_{\mathrm{Si}-\mathrm{H}} \cdot I,
$$

where

$$
I=\int \frac{\alpha}{\varpi} d \varpi
$$

where $\alpha$ is the absorption coefficient, $\varpi$ is the frequency (wave number) in $\mathrm{cm}^{-1}$, and integration is performed over the entire absorption band. $A_{\mathrm{Si}-\mathrm{H}}$ is a calibration constant which relates the integrated absorption with the total hydrogen concentration. For $\mathrm{Si}-\mathrm{H}$ stretching vibrations above $2100 \mathrm{~cm}^{-1}$, the value of this constant has been determined in literature ${ }^{23}$ to be $(2.1 \pm 0.15) \times 10^{20} \mathrm{~cm}^{-2}$ so this is the value that we have used in this work.

The total hydrogen concentration versus RTA temperature for a near-stoichiometric film is presented in Fig. 6(a). The total amount of hydrogen suffers an slight increase for

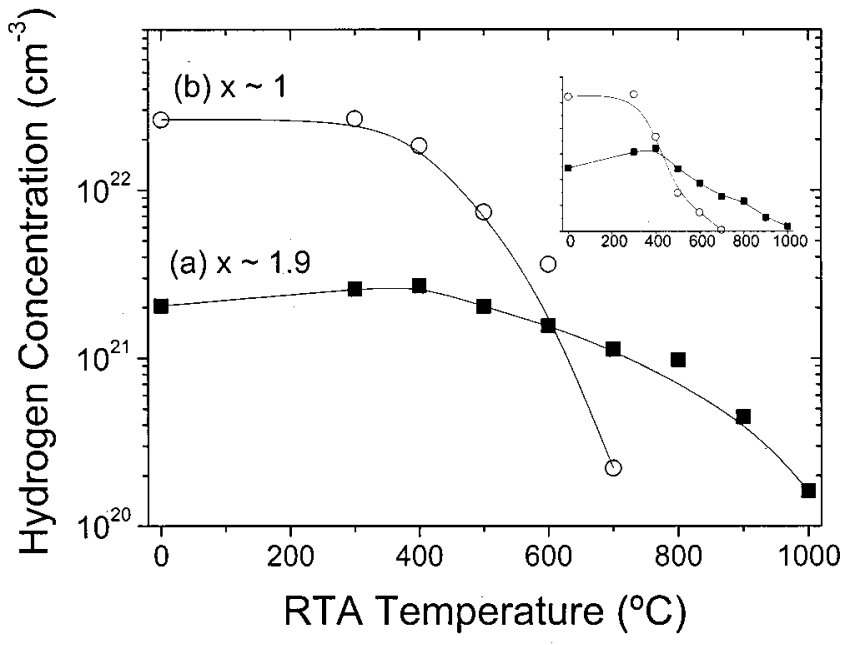

FIG. 6. Hydrogen concentration (logarithmic scale) versus RTA temperature for a near-stoichiometric film ( $\mathrm{a}, x \approx 1.9)$, and an off-stoichiometric film (b, $x \approx 1.0$ ) (inset: same data in a linear scale. The values or the two samples are not in proportion). Lines are drawn as a guide for the eye.

low RTA temperatures, reaching a maximum when annealing at $400{ }^{\circ} \mathrm{C}$, as is shown in the inset of Fig. 6, where the hydrogen concentration is presented in a linear scale. For higher RTA temperatures, the hydrogen is released with an activation energy of the process of $0.23 \mathrm{eV}$ (extracted via the Arrhenius fit of the FTIR Si- $\mathrm{H}$ stretching area against RTA temperature), being almost completely lost for a RTA temperature of $1000^{\circ} \mathrm{C}$.

The three off-stoichiometric films analyzed undergo a completely different behavior with the RTA. The $\mathrm{Si}-\mathrm{O}-\mathrm{Si}$ peak position did not change up to RTA temperatures of $600^{\circ} \mathrm{C}-700^{\circ} \mathrm{C}$. For $T>700^{\circ} \mathrm{C}$, the $\mathrm{Si}-\mathrm{O}-\mathrm{Si}$ stretching band shifts progressively to the $\mathrm{SiO}_{2}$ value. At the RTA temperature of $1000{ }^{\circ} \mathrm{C}$, all analyzed samples exhibited the peak position in the $1070-1085 \mathrm{~cm}^{-1}$ range. This margin has been reported to be in the range of the stretching band values for $\mathrm{SiO}_{2}$ films. ${ }^{18,24}$ The dependence of the FWHM with RTA is also completely different from that exhibited for both the $\mathrm{SiO}_{2}$ film and the near-stoichiometric one. Up to $700^{\circ} \mathrm{C}$, the FWHM increases with RTA temperature and for higher values, the FWHM decreases, but for the range of annealing temperatures studied the FWHM is always above $110 \mathrm{~cm}^{-1}$. Concerning the behavior under annealing of the hydrogen present in these off-stoichiometric films, the total amount of bonded hydrogen for an off-stoichiometric film with $x \approx 1$ is depicted in Fig. 6(b). The hydrogen was released in the $400{ }^{\circ} \mathrm{C}-700{ }^{\circ} \mathrm{C}$ range with activation energy of $0.41 \mathrm{eV}$. The other off-stoichiometric films analyzed presented the same behavior, with activation energies between 0.21 and $0.41 \mathrm{eV}$, but without clear relation between film composition and the value of activation energy for the $\mathrm{H}$ release. As was shown in Figs. 5(c) and 5(d), the RTA process did not change the $\mathrm{Si}-\mathrm{H}$ stretching and bending peak positions during the hydrogen effusion for any of the analyzed films.

In Fig. 7, we present the results of ESR measurements for three representative compositions $[x \approx 2,1.9$, and 1 corresponding to Fig. 7(a), 7(b), and 7(c), respectively] of as- 


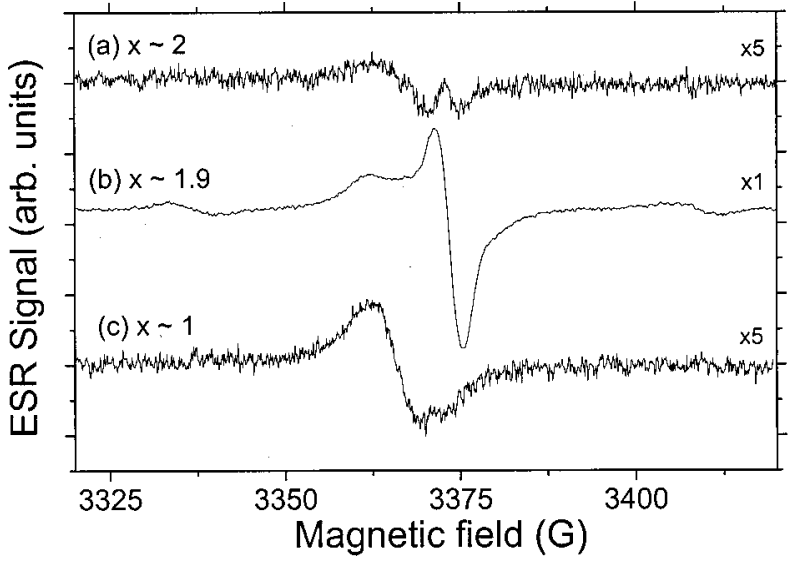

FIG. 7. ESR spectra of three significant as-deposited film compositions: stoichiometric (a), near stoichiometric (b), and off-stoichiometric (c).

deposited samples. Other off-stoichiometric compositions exhibited almost quantitative agreement with data obtained for the $x \approx 1$ composition, so for the sake of clarity, only the results of this last one are presented. The spectra show two clear different lines:

A narrow line with $g$ ranging from 2.0004 to 2.0010 and width (peak-to-peak first derivative) $\Delta H_{\mathrm{pp}}$ about 3-5 G. This line can be assigned to the well-known $E^{\prime}$ center, whose origin is essentially a silicon dangling bond with $\cdot \mathrm{Si} \equiv \mathrm{O}_{3}$ configuration. ${ }^{25,26}$

(ii)

Another wider line $\left(\Delta H_{\mathrm{pp}}\right.$ around 6-9 G) with $g$ value in the range $2.0045-2.0055$. There are two reported defects in literature with similar features to this line: The bulk silicon dangling bond center in - $\mathrm{Si} \equiv \mathrm{Si}_{3}$ configuration, that some authors call $D$ center $^{26}$ and the well known interface $P_{b}$ center $\left(\bullet \mathrm{Si} \equiv \mathrm{Si}_{3}\right.$ at the $\mathrm{SiO}_{2} / \mathrm{Si}$ interface with a $g$ value of 2.005). ${ }^{27}$ We will name the defect observed in our samples as $\mathrm{Si}_{D B}$.

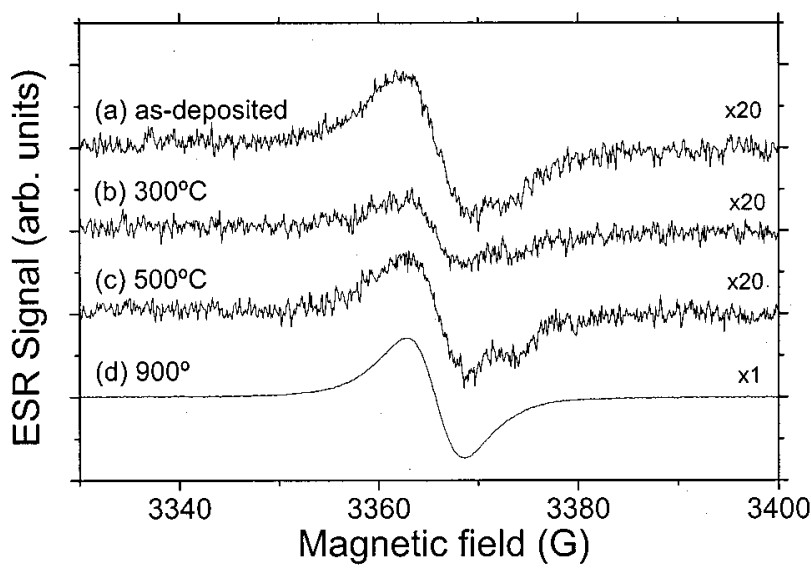

FIG. 8. ESR spectra for an off-stoichiometric film as deposited (a), annealed at $300{ }^{\circ} \mathrm{C},(\mathrm{b}), 500^{\circ} \mathrm{C}(\mathrm{c})$, and $900^{\circ} \mathrm{C}(\mathrm{d})$.

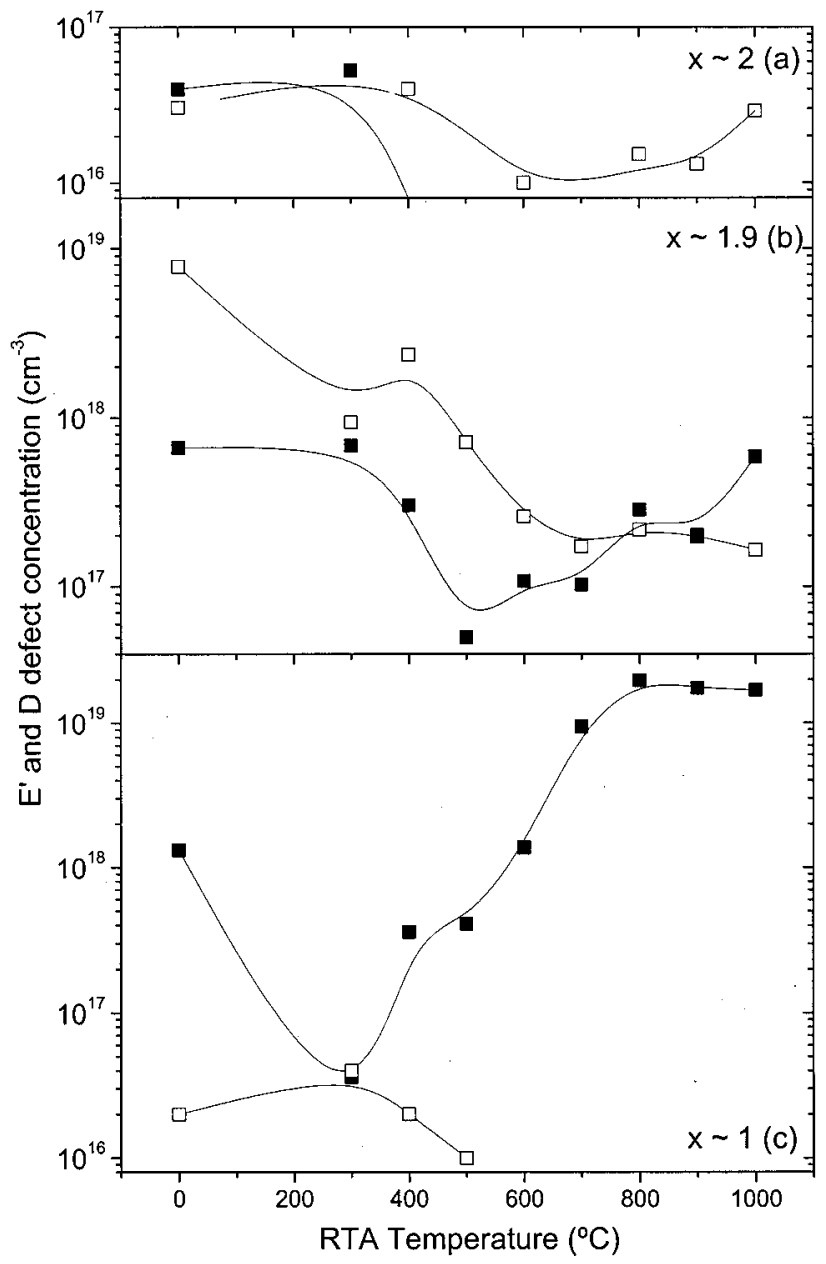

FIG. 9. Concentration of $E^{\prime}$ and $\mathrm{Si}_{D B}$ defects as a function of RTA temperature for three significant film compositions: stoichiometric (a), near stoichiometric (b), and off-stoichiometric (c). Open squares ( $\square$ ) stand for $E^{\prime}$ defects and filled ones $(\boldsymbol{\square})$ stand for $\mathrm{Si}_{D B}$ defect concentration. Lines are drawn as a guide for the eye.

The concentration of each defect is strongly dependent on film composition, ${ }^{28}$ as observed in Fig. 7. From the deconvolution of the spectra in Fig. 7, the concentration of each defect can be obtained.

The evolution of the ESR signal with RTA temperature is presented in Fig. 8 for an off-stoichiometric film $(x \approx 1)$. The as-grown film present $E^{\prime}$ and $\mathrm{Si}_{D B}$ defects, but their behavior with annealing is very different: while the $E^{\prime}$ center is present in a low concentration in the as-deposited film, disappearing with increasing RTA temperature, the $\mathrm{Si}_{D B}$ center concentration decreases when annealing at $300{ }^{\circ} \mathrm{C}$, then increases with temperature to reach the $10^{19} \mathrm{~cm}^{-3}$ range for RTA temperatures above $800^{\circ} \mathrm{C}$. The RTA did not significantly changed neither $g$ nor $\Delta H_{\mathrm{pp}}$ values for the two types of defects present in the films.

The results of the concentration of each defect versus RTA temperature for the three kinds of films studied $(x \approx 2$, $x \approx 1.9$ and $x \approx 1$ ) are drawn in Figs. 9(a), 9(b), and 9(c), respectively.

In $\mathrm{SiO}_{2}$ films [Figs. 7(a) and 9(a)], both the $E^{\prime}$ and $\mathrm{Si}_{D B}$ defect were present, with a concentration previous to the RTA treatment in the $(2-3) \times 10^{16} \mathrm{~cm}^{-3}$ range for the $E^{\prime}$ 
and $(4-5) \times 10^{16} \mathrm{~cm}^{-3}$ for the $\mathrm{Si}_{D B}$. As can be seen in Fig. 9(a), the $E^{\prime}$ concentration shows a slight dependence with the annealing, but its concentration remains in the range of $(3-4) \times 10^{16} \mathrm{~cm}^{-3}$ for all temperatures, reaching a minimum of $1.0 \times 10^{16} \mathrm{~cm}^{-3}$ for a RTA temperature of $500{ }^{\circ} \mathrm{C}$. Concerning the behavior of the $\mathrm{Si}_{D B}$, this defect disappears at RTA temperature as low as $400^{\circ} \mathrm{C}$. These results are similar to the data previously reported by our group for stoichiometric oxides. ${ }^{15}$

In all other film types (i.e., the near-stoichiometric sample, Fig. 9(b), and the off-stoichiometric one, Fig. 9(c), both $E^{\prime}$ and $\mathrm{Si}_{D B}$ centers were present with the unannealed concentration dependent on the initial film composition ${ }^{27,28}$ but the behavior with the annealing was different to the one described herein for $\mathrm{SiO}_{2}$. The near-stoichiometric samples [Fig. 9(b)] present a continuous decrease in the $E^{\prime}$ center, while the $\mathrm{Si}_{D B}$ center concentration decreases for the lowest RTA temperatures reaching a minimum of $5 \times 10^{16} \mathrm{~cm}^{-3}$ at $500{ }^{\circ} \mathrm{C}$ and increasing monotonically for annealing temperatures above $600{ }^{\circ} \mathrm{C}$. The behavior of the nonstoichiometric films has a similar trend: The concentration of the $E^{\prime}$ defect decreases with the annealing and vanishes at RTA temperatures above $700{ }^{\circ} \mathrm{C}$, while the concentration of $\mathrm{Si}_{D B}$ defects decreases when annealing at $300{ }^{\circ} \mathrm{C}$, and then monotonically increases for temperatures between $400^{\circ} \mathrm{C}-800^{\circ} \mathrm{C}$. At higher temperatures, the $\mathrm{Si}_{D B}$ concentration saturates in the $10^{19} \mathrm{~cm}^{-3}$ range. It should be remarked that for all of the off-stoichiometric samples analyzed, the behavior with the annealing of the $\mathrm{Si}_{D B}$ defect was similar to that found for the $x \approx 1.9$ sample shown in Fig. 9(b), but the saturation value was about one order of magnitude higher than the exhibited for this sample. The behavior upon annealing described herein is different from recently published results for films of similar compositions. ${ }^{13}$

\section{DISCUSSION}

We will now discuss all the results described attending to the initial composition of the different samples analyzed.

The behavior of $\mathrm{SiO}_{2}$ film with the annealing can be explained as reported elsewhere. ${ }^{15}$ It is due to a trend toward an increase in the structural order induced by the RTA. Since the main objective of this article is focused on off-stoichiometric $\mathrm{SiO}_{x}: \mathrm{H}$ films, we do not offer further explanations here (see Ref. 15).

(ii) From the structural point of view, there are no significant differences between near-stoichiometric film and the $\mathrm{SiO}_{2}$ film as Figs. 3 and 4 evidence. The only difference is a small amount of bonded hydrogen, that seems to play a major role in the defect behavior with the annealing. The presence of this hydrogen makes the defect concentration follow a similar trend to the off-stoichiometric films, as was quoted in Sec. III. Due to this similarity, the ESR results obtained for these samples will be explained together with the offstoichiometric films in the next paragraph.

(iii) Concerning off-stoichiometric films, from the structural point of view, the results of Figs. 3 and 4 can be explained as follows:
At annealing temperatures below $700{ }^{\circ} \mathrm{C}$, films release the hydrogen without compositional changes, as is deduced from the fact that $\mathrm{Si}-\mathrm{O}-\mathrm{Si}$ peak position remains unchanged with the temperature (see Fig. 3) and the fact that the $\mathrm{Si}-\mathrm{H}$ bonding peaks also remain unchanged in position (see Fig. 5). The results of Fig. 4 for the FWHM (increasing values of this parameter in the $400{ }^{\circ} \mathrm{C}-700{ }^{\circ} \mathrm{C}$ annealing range) suggest that, following Ref. $26, \mathrm{Si}-\mathrm{O}$ bonds are formed after the hydrogen release and that this process occurs with the induction of structural disorder on the films. An exception to this rule appears for the near-stoichiometric film $(x \approx 1.9)$, where the small amount of hydrogen present seems to be released without significant structural changes.

We explain these results according to the following network reaction:

$$
\mathrm{H}-\mathrm{Si}-\mathrm{O}+\mathrm{H}-\mathrm{Si}-\mathrm{O} \rightarrow \mathrm{H}_{2} \uparrow+2(\mathrm{Si}-\mathrm{O}) .
$$

Reaction (4) accounts for the hydrogen release of both near and off-stoichiometric films, that occurs without changes in the oxygen to silicon ratio in agreement with Figs. 3 and 5. Since the hydrogen release occurs via network reactions, the measured activation energy for the process $(0.21-0.41 \mathrm{eV})$ is much lower than bonding energy of $\mathrm{Si}-\mathrm{H}$ bonds $(3.7 \mathrm{eV}){ }^{16}$ The initial decrease in the detected $\mathrm{Si}_{D B}$ defect concentration for low annealing temperatures may be due to two different processes: (i) there may be a thermally activated charge transfer between the network and the paramagnetically active defect, making the defect diamagnetic and thus undetectable via ESR measurement, ${ }^{29}$ or (ii) some interstitial hydrogen may follow a network reaction with not totally bonded silicon as is suggested by the inset of Fig. 6 . There, the hydrogen concentration versus RTA temperature is shown in a linear scale, and the increase in hydrogen concentration in the low-temperature range can be easily observed, which is relatively more important in the nearstoichiometric film. In this way, some of this hydrogen may passivate few $\mathrm{Si}_{D B}$ defects. ${ }^{28}$ We can not decide whether this last process is responsible for the decrease in the $\mathrm{Si}_{D B}$ defect concentration or not, because of the different orders of magnitude of the $\mathrm{Si}-\mathrm{H}$ bonding concentration increase measured by FTIR and of the $\mathrm{Si}_{D B}$ defect concentration decrease, as obtained by ESR.

On the other hand, at annealing temperatures higher than $700{ }^{\circ} \mathrm{C}$, the results of Fig. 3 suggest the formation of $\mathrm{SiO}_{2}$, as the peak position of the $\mathrm{Si}-\mathrm{O}-\mathrm{Si}$ stretching band shifts to the stoichiometric value. ${ }^{1}$ This is also in agreement with results of Fig. 4, where a reduction in the FWHM at this temperature range can be seen. It may also indicate that bonds with low mode frequencies are decreasing, suggesting that $\mathrm{SiO}_{x}$ films experience changes to $\mathrm{Si}$ and $\mathrm{SiO}_{2} \cdot{ }^{30}$ The results of Fig. 9 confirm this hypothesis, since the concentration of the main defect present in $\mathrm{SiO}_{2}$ films, the $E^{\prime}$ defect, disappears at this temperature range, suggesting again the formation of high-quality, almost defect-free $\mathrm{SiO}_{2}$ film. The formation of this $\mathrm{SiO}_{2}$ matrix occurs without changes in the whole oxygen to silicon ratio of films, as results of Fig. 5 evidence. The very high values of the FWHM (Fig. 4) and the presence of a high concentration of the $\mathrm{Si}_{D B}$ defect in all the off-stoichiometric films (Fig. 9), clearly indicates that 
these films undergo structural modifications in such a way that the formation of $\mathrm{SiO}_{2}$ is accompanied with the formation of highly defective silicon clusters where the $\mathrm{Si}_{D B}$ centers agglomerate. This has been explained in literature by the formation of nc-Si. ${ }^{1-3}$ A network reaction similar to Eq. (1) can explain this process:

$$
\mathrm{Si}-\mathrm{O}+\mathrm{Si}-\mathrm{O} \rightarrow \mathrm{SiO}_{2}+\text { nc-Si. }
$$

Keeping in mind that at high RTA temperatures the $E^{\prime}$ center disappears (Fig. 9), and being this center characteristic of stoichiometric $\mathrm{SiO}_{2}$, we deduce that the increase of $\mathrm{Si}_{D B}$ centers occurs in the nc-Si. The results of Figure 9 also suggest that these nc-Si act as getters for the $\mathrm{Si}_{D B}$ defects. Due to the similar characteristics of $g$ value and shape of the spectra of bulk $D$ centers ${ }^{26}$ and interface $P_{b}$ centers, ${ }^{27}$ it is not possible to assure whether the $\mathrm{Si}_{D B}$ center are located only at the interface of the nc-Si with the $\mathrm{SiO}_{2}$ surrounding matrix (being then the $\mathrm{Si}_{D B}$ defect the $P_{b}$ type), as some authors propose, ${ }^{31}$ or they are present also in the bulk of the nc-Si (being now the $D$ defect). Our results suggest that the measured concentration of $\mathrm{Si}_{D B}$ centers seems to be in a straightforward relation with the hydrogen release process that these films experience accordingly with Eq. [4]. From our data, we can not discern whether these centers are in the surface of the nc-Si or in its bulk, but being the hydrogen release a bulk effect, we propose that the $\mathrm{Si}_{D B}$ is mainly composed of bulk $D$-type centers.

In this way, the results of ESR measurements seem to indicate that the thermal treatment carried out on $\mathrm{SiO}_{x}: \mathrm{H}$ films promotes the formation of a high-quality, almost defect-free $\mathrm{SiO}_{2}$ matrix, in which highly defective nc-Si are embedded. In the near-stoichiometric film, the amount of these nc-Si clusters would be small and, as a consequence, the structural characteristics of this film after the annealing are almost identical to those of $\mathrm{SiO}_{2}$ films. Also, after the annealing the concentration of $D$ defects is lower than in off-stoichiometric samples.

On the other hand, on films with initial offstoichiometric compositions $(x \approx 1.4,1$, and 0.9$)$, the annealing promotes the formation of a great number of highly defective nc-Si, as the results showed in Fig. 9(c) for the $D$ defect concentration evidence. Then, the structural characteristics of these films after the annealing are very different from both the $\mathrm{SiO}_{2}$ film and the near-stoichiometric one. The main influence of these differences accounts for the high values of the FWHM that these films present after the annealing.

\section{CONCLUSIONS}

Summarizing, we have deposited, by the ECR plasma method, $\mathrm{SiO}_{x}: \mathrm{H}$ films of different compositions (from $x$ $\approx 0.9$ to $x \approx 2$ ) and subjected them to RTA treatments. The stoichiometric films present the well known shift with RTA temperature of the $\mathrm{Si}-\mathrm{O}$ bond stretching vibration. Also they present $E^{\prime}$ and $D$ defects in a low concentration (2-5 $\times 10^{16} \mathrm{~cm}^{-3}$ ). The near-stoichiometric film presents a small amount of hydrogen, and their ESR defects and concentrations follow a similar behavior to off-stoichiometric samples.
After annealing, the off-stoichiometric films experience two different processes, depending on annealing temperature. Up to $700^{\circ} \mathrm{C}$, films release the hydrogen, without modification of the oxygen to silicon ratio of films, as is demonstrated by their FTIR spectra. The concentration of defects present in the films (both $E^{\prime}$ and $D$ ) experience an initial decrease, followed by a significant increase of the $D$ center and the annihilation of the $E^{\prime}$ defect. Annealing this film at temperatures in the $700{ }^{\circ} \mathrm{C}-1000^{\circ} \mathrm{C}$ range induces the formation of a high-quality $\mathrm{SiO}_{2}$ matrix, almost defect free, in which nc-Si is embedded. The ESR characterization shows that the nc-Si is highly defective (the concentration of $D$ centers is in the $10^{19} \mathrm{~cm}^{-3}$ range). Depending on the initial composition of $\mathrm{SiO}_{x}: \mathrm{H}$ films, the number of these nanocrystals is different, being higher in the films with lower values of $x$. In this type of film, the nc-Si influences the structural characteristics of films (high values of the FWHM of the $\mathrm{Si}-\mathrm{O}-\mathrm{Si}$ stretching band). On the other hand, on films with $x \approx 1.9$, the $\mathrm{nc}-\mathrm{Si}$ concentration should be low and then the FWHM of the stretching band is not influenced by the nanocrystals.

\section{ACKNOWLEDGMENTS}

The authors acknowledge CAI de Implantación Iónica (UCM) for technical support and C.A.I. de Espectroscopía (UCM) for the availability of the FTIR spectrometer. This work was partially supported by the Spanish CICYT, under Contract No. TIC 01-1253.

${ }^{1}$ B. J. Hinds, F. Wang, D. M. Wolfe, C. L. Hinkle, and G. Lucovsky, J. Vac. Sci. Technol. B 16, 2171 (1998).

${ }^{2}$ K. Furukawa, Y. Liu, H. Nakashima, D. Gao, K. Uchino, K. Muraoka, and H. Tsuzuki, Appl. Phys. Lett. 72, 725 (1998).

${ }^{3}$ G. B. Alers, D. J. Werder, Y. Chabal, H. C. Lu, E. P. Gusev, E. Garfunkel, T. Gustafsson, and R. S. Urdahl, Appl. Phys. Lett. 73, 1517 (1998).

${ }^{4}$ H.-S. Kim, IEEE Electron Device Lett. 18, 465 (1997).

${ }^{5}$ Q. X. Jia, J. L. Smith, L. H. Chang, and W. A. Anderson, Philos. Mag. B 77, 1163 (1997)

${ }^{6}$ G. Lucovsky, Y. Wu, H. Niimi, V. Misra, and J. C. Philips, Appl. Phys. Lett. 74, 2005 (1999).

${ }^{7}$ G. Lucovsky, J. Non-Cryst. Solids 1, 227 (1998).

${ }^{8}$ F. Rochet, G. Dufour, H. Roulet, B. Pelloie, J. Perrière, E. Fogarassy, A. Slaoui, and M. Froment, Phys. Rev. B 37, 6468 (1988).

${ }^{9}$ C.-F. Lin, W.-T. Tseng, and M. Shiann Feng, J. Appl. Phys. 87, 2808 (2000).

${ }^{10}$ G. Franzò, A. Irrera, E. C. Moreira, M. Miritello, F. Iacona, D. Sanfilippo, G. Di Stefano, P. G. Fallica, and F. Priolo, Appl. Phys. A: Mater. Sci. Process. 74, 1 (2002).

${ }^{11}$ U. Kahler and H. Hofmeister, Appl. Phys. A: Mater. Sci. Process. 74, 13 (2002).

${ }^{12}$ E. San Andrés, A. del Prado, I. Mártil, G. González-Díaz, F. L. Martínez, D. Bravo, and F. J. López, Vacuum (to be published).

${ }^{13}$ R. C. Barklie, M. Collins, M. Richardson, and I. Borde, J. Mater. Sci.: Mater. Electron. 12, 231 (2001).

${ }^{14}$ A. Borghesi, A. Sassella, B. Pivac, and L. Zanotti, Solid State Commun. 100, 657 (1996)

${ }^{15}$ E. San Andrés, A. Del Prado, F. L. Martinez, I. Mártil, D. Bravo, and F. J. López, J. Appl. Phys. 87, 1187 (2000).

${ }^{16}$ F. L. Martinez, A. Del Prado, I. Mártil, G. González Díaz, W. Bohne, W. Fuhs, J. Rörich, B. Selle, and I. Sieber, Phys. Rev. B 63, 245320 (2001).

${ }^{17}$ P. V. Bulkin, P. L. Swart, and B. M. Lacquet, J. Non-Cryst. Solids 58, 226 (1998).

${ }^{18}$ D. V. Tsu, G. Lucovsky, and B. N. Davidson, Phys. Rev. B 40, 1795 (1989).

${ }^{19}$ F. L. Martinez, E. San Andrés, A. Del Prado, I. Mártil, D. Bravo, and F. J. López, J. Appl. Phys. 90, 1573 (2001). 
${ }^{20}$ G. Lucovsky, J. Yang, S. S. Chao, J. E. Tyler, and W. Czubatyj, Phys. Rev. B 28, 3225 (1983).

${ }^{21}$ M. Zacharias, D. Dimova-Malinovska, and M. Stutzmann, Philos. Mag. B 73, 799 (1996).

${ }^{22}$ G. Lucovsky, Solid State Commun. 29, 571 (1979).

${ }^{23}$ A. A. Langford, M. L. Fleet, B. P. Nelson, W. A. Lanford, and N. Maley, Phys. Rev. B 45, 13367 (1992).

${ }^{24}$ H. Nakashima, K. Furukawa, Y. C. Liu, D. W. Gao, Y. Kashiwazaki, K. Muraoka, K. Shibata, and T. Tsurushima, J. Vac. Sci. Technol. A 15, 1951 (1997).

${ }^{25}$ P. M. Lenahan and J. F. Conley Jr., J. Vac. Sci. Technol. B 16, 2134 (1998).
${ }^{26}$ T. Inokuma, L. He, Y. Kurata, and S. Hasegawa, J. Electrochem. Soc. 142, 2346 (1995)

${ }^{27}$ M. J. Uren, J. H. Stathis, and E. Cartier, J. Appl. Phys. 80, 3915 (1996).

${ }^{28}$ E. San Andrés, A. del Prado, I. Mártil, G. González-Díaz, F. L. Martínez, D. Bravo, F. J. López, and M. Fernández, Vacuum (to be published).

${ }^{29}$ F. L. Martínez, A. del Prado, I. Mártil, D. Bravo, and F. J. López, J. Appl. Phys. 88, 2149 (2000).

${ }^{30}$ K. Furukawa, Y. Liu, H. Nakashima, D. Gao, K. Uchino, K. Muraoka, and H. Tsuzuki, Appl. Phys. Lett. 72, 725 (1998).

${ }^{31}$ M. López, B. Garrido, C. García, P. Pellegrino, A. Pérez-Rodríguez, J. R. Morante, C. Bonafos, M. Carrada, and A. Claverie, Appl. Phys. Lett. 80, 1637 (2002). 